\title{
First case of Trichinella nativa infection in wild boar in Central Europe-molecular characterization of the parasite
}

\author{
Ewa Bilska-Zając ${ }^{1}$ - Mirosław Różycki ${ }^{1}$ Ewa Chmurzyńska ${ }^{1}$ - Ewelina Antolak ${ }^{1}$. \\ Marek Próchniak $^{1}$ - Katarzyna Grądziel-Krukowska ${ }^{1}$. Jacek Karamon ${ }^{1}$. \\ Jacek Sroka $^{1}$ - Jolanta Zdybel ${ }^{1}$ - Tomasz Cencek ${ }^{1}$
}

Received: 15 February 2017 / Accepted: 12 April 2017 /Published online: 25 April 2017

(C) The Author(s) 2017. This article is an open access publication

\begin{abstract}
The examination of wild boars gained in Poland shows for the first time occurrence of Trichinella nativa, freeze-resistant species of Trichinella in this host from the central Europe region. This finding is not only one of several cases of T. nativa invasion in wild boars all over the world but also one of the very few cases of T. nativa detected so far beyond the known boundary of occurrence of this species. The molecular characterization of discovered larvae based on analysis of partial genes: $5 \mathrm{~s}$ rDNA-ISR and CO1 confirm the findings. Moreover, the analyzed DNA sequences of both genes present new haplotypes of T. nativa in comparison to that described previously.
\end{abstract}

Keywords Trichinella nativa $\cdot$ Wild boars $\cdot$ Haplotype $\cdot 5 \mathrm{~s}$ rDNA-ISR $\cdot$ CO1

\section{Introduction}

Nematodes of the genus Trichinella are zoonotic parasites with a high impact on human health and animal trade (Gottstein et al. 2009). Till now, 12 taxa in this genus are recognized and divided into two clades: encapsulated and non-encapsulated ones. From these 12 known taxa, 4 are circulating in Europe, 3 encapsulated (Trichinella spiralis, Trichinella nativa, Trichinella britovi) and one nonencapsulated (Trichinella pseudospiralis) (Pozio and Zarlenga 2013). All of them are infective to human and

Ewa Bilska-Zając

ewa.bilska@piwet.pulawy.pl

1 National Veterinary Research Institute in Puławy, Partyzantów Avenue 57, 24-100 Puławy, Poland consumption of meat with live larvae poses a risk of trichinellosis for humans.

Individual species differ by their properties and zoonotic potential. These characters influence the risk assessment in humans and may affect the development of new sanitary and veterinary regulations. For example, discovery of the T. pseudospiralis in wild boars in Poland (Bilska-Zajac et al. 2016) resulted in the limitation of the compressor method use in endemic regions. Information on Trichinella species occurring in the country is also important for veterinary services of third countries in the supervision of imports of food of animal origin. Therefore, compulsory examination for trichinellosis in accordance with Commission Implementing Regulation (EU) 2015/1375 of 10 August 2015 laying down specific rules on official controls for Trichinella in meat, has two phases and includes meat inspection to detect larvae and, in the case of positive results, identification of Trichinella species causing the invasion. In Poland routine inspection (detection of parasites) of meat from pigs, wild boars, coypus, and horses is provided by veterinary inspection services. The National Veterinary Research Institute as a national reference laboratory for trichinellosis in Poland is responsible for confirmation of positive results and species identification. From four routinely examined animal species, trichinellosis is discovered the most often in wild boars. It should be stressed that in the last decade, human trichinellosis was caused by ingestion of meat from illegally hunted and not-examined Trichinella-infected wild boars only.

It should be taken into consideration that the wild boar population in Poland increased from the last two decades from 90,000 up to 300,000 (Popczyk 2016). With the increase of the population, the number of Trichinella-infected animals is rising and now achieved over 600 positive animals per year. Up to 2012, only two species: T. spiralis and T. britovi were discovered in wild boars in Poland (Bilska-Zając et al. 2013). 
Since 2012, a few cases of T. pseudospiralis were also detected (Bilska-Zajac et al. 2016). However, to date, T. nativa discovered in few Northeastern European countries, was never detected in wild boars in Poland. Until now, this species was detected in Poland only once in red fox (Chmurzynska et al. 2013).

From January to September 2016, 300 muscle samples from wild boars previously recognized by VIS laboratories as Trichinella positive were delivered to NVRI for species identification. The species identification was done by multiplex PCR according to the protocol of European Reference Laboratory for Parasites. Altogether, 235 samples were identified as T. spiralis (78.4\%), 57 samples as T. britovi (19\%), and in 7 samples the mixed infection T. spiralis/T. britovi was recognized $(2.3 \%)$. One sample was identified as $T$. nativa $(0.3 \%)$. The sample of T. nativa was originated from wild boar gained in Ławice, district Iława, Varmian Masurian province. The infected wild boar was female, close to 2 years old, and weight of carcass after removing of the guts were about $40 \mathrm{~kg}$. Intensity of invasion was evaluated as one larvae per $10 \mathrm{~g}$ of muscle tissue. Because this was the first finding of T. nativa in wild boar in Poland (and Central Europe) we aimed to perform the genetic analysis of isolated larvae.

\section{Material and methods}

For the study, five larvae extracted from the muscle of the positive wild boar were used. The DNA from each larvae were separately extracted using commercial kit according to manufacturer protocol (Promega, USA). The recognition of species were provide by multiplex PCR method according to European Reference Laboratory method (Zarlenga et al. 1999).The PCR products were separated electrophoretically in $1.5 \%$ agarose gel and stained with Simply Safe (EURx, Polska). DNA bands in gel were visualized under UV light. For every PCR, negative (nuclease-free water) and positive (reference Trichinella larvae ISS3, ISS2, or ISS13 from EURLP) controls were used.

Subsequently, DNA of each T. nativa larvae was designated for molecular characterization. The part of 5S ribosomal DNA intergenic spacer region (5s rDNA-ISR) and fragment of mitochondrial cytochrome c oxidase 1 (CO1) gene were amplified for confirmation of species identification and molecular characterization of detected T. nativa. For amplification of 5s rDNA-ISR, forward primer 5'GCGAATTCTTGGATCGGAGACGGCCTG and reverse primer 5'-GCTCTAGACGAGATGTCGTGCTTTCAACG as described earlier by Liu et al. (1996) and Rombout et al. (2001b) were used (Liu et al. 1996; Rombout et al. 2001a). The expected PCR products were approximately 750 base pairs. A second PCR was performed to amplify the CO1 gene, using forward primer 5'-TACC
TATACTACTAAGAGGATTCGGA and reverse primer 5'-CTAGTACTCATAGTATGGCTGGTG previously designed by Franssen et al. (2015). The amplification results in products of approximately $760 \mathrm{bp}$. For amplification of both $5 \mathrm{~s}$ rDNA-ISR and $\mathrm{CO} 1$ gene, the same condition and mix reagents were used as described below. Polymerase chain reactions were performed in $50-\mu \mathrm{L}$ volume containing $4 \mu \mathrm{L}$ of extracted DNA, $30 \mu \mathrm{L}$ of GoTaq G2 Master Mix (Promega, USA), and $0.5 \mu \mathrm{L}$ of each primers $(10 \mathrm{mM})$. The PCR conditions were as follows: denaturation at $95{ }^{\circ} \mathrm{C}$ for 15 min followed by 40 cycles of $95^{\circ} \mathrm{C}$ for $1 \mathrm{~min}, 50^{\circ} \mathrm{C}$ for $1 \mathrm{~min}, 72^{\circ} \mathrm{C}$ for $1 \mathrm{~min}$ and $30 \mathrm{~s}$, and a final elongation step of $72{ }^{\circ} \mathrm{C}$ for $10 \mathrm{~min}$. The PCR products were separated elecrophoretically in $2 \%$ agarose gel with Simply Safe dye. DNA bands in gel were visualized under UV light. PCR products were purified using ExoSAP (Affymetrix, UK) according to manufacturer procedure and sent for sequencing to Genomed-sequence company.

Sequence and phylogeny analysis were done using available computer software. Forward and reverse sequences were aligned and edited manually using the Geneious R7 (Kearse et al. 2012). The consensus sequences of 5 s rDNA-ISR were applied for alignment. Moreover, for the analysis, 5s rDNAISR sequences of T. spiralis (GenBank Accessions KJ716745, AY009946); T. britovi (GenBank Accession AY009943, GU325734, GU325737); T. nativa (GenBank Accession AY009944); T. murelli (GenBank Accession AB426627); T6 (GenBank Accession AY009948); T8 (GenBank Accession AY009949); T9 (GenBank Accession KP900345); and T. pseudospiralis (GenBank Accession AY009943) were used.

Analogical analysis was performed using the consensus of mitochondrial $\mathrm{CO} 1$ sequences. For the alignment the $\mathrm{CO} 1$ sequences of T. spiralis (GenBank Accessions KM357422, KU321693, KU321694, KU321695); T. britovi (GenBank Accessions KP900334, KP900335, KP900336, NC025750, KM377413); T. nativa (GenBank Accessions KU375850 KU375861, KU375874, KM357415, AP017702); T. murelli (GenBank Accession NC025751); T6 (GenBank Accession KM357418); T9 (GenBank Accession KP900338) and T. pseudospiralis (GenBank Accession NC025749) were used. Subsequently, phylogenetic analysis of consensus sequences was performed using the Neighbor-Joining method with Jukes-Cantor model and MrByes method in Geneious R7 (Figs. 1, 2).

\section{Results}

The amplification of DNA from investigated larvae resulted in multiplex PCR in band $127 \mathrm{bp}$ for all five larvae. The result indicate on singular infection of T. nativa. Subsequently, the 
Fig. 1 Phylogenetic tree of the partial of $5 \mathrm{~s}$ rDNA-ISR gene sequences from the Trichinella larvae. The phylogenetic tree was constructed using MrBayes with burn in $=100,000$. The tree constructed using the NeighborJoining method with JukesCantor model shows identical results, data not shown analyses running the HKY model

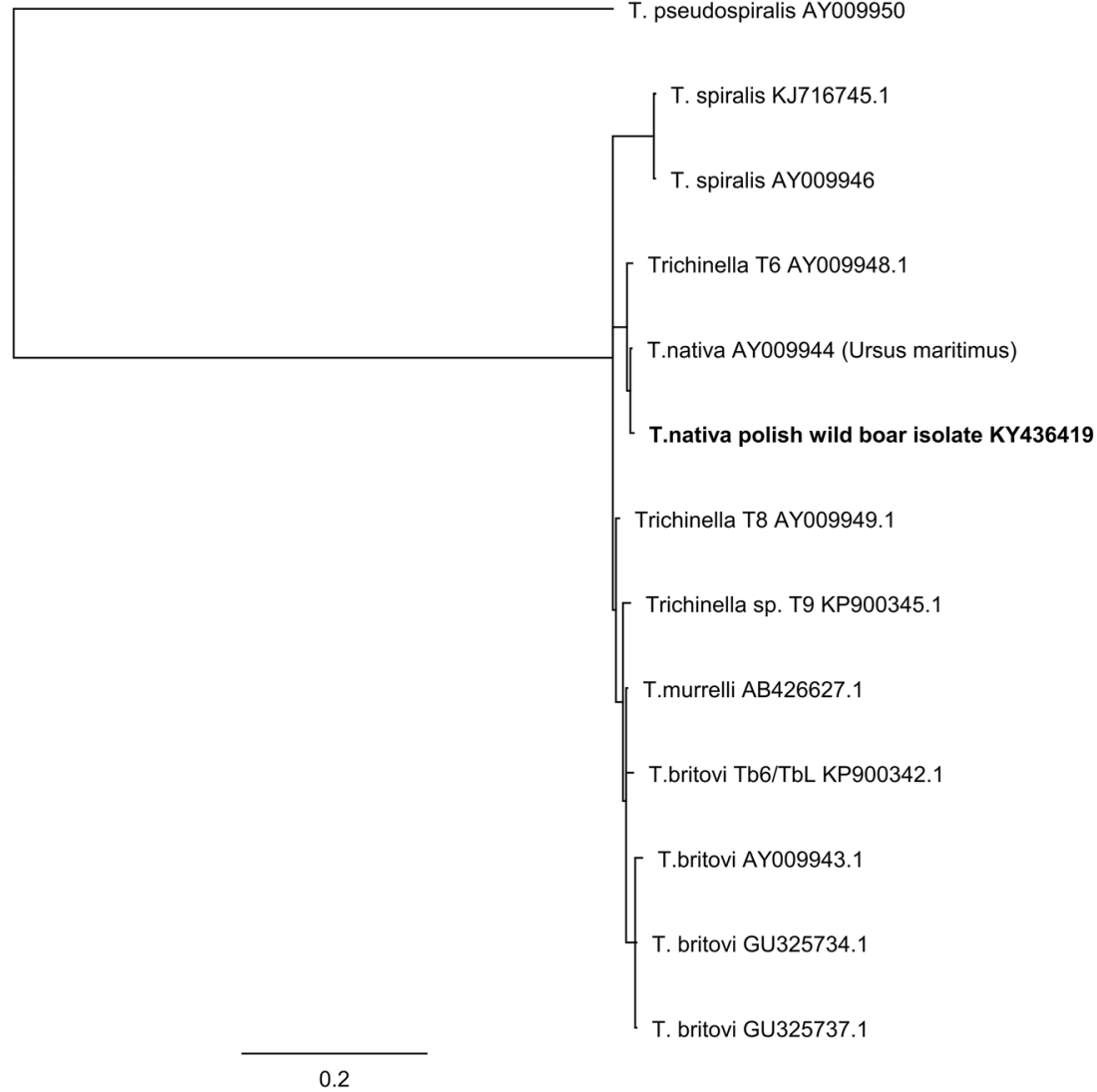

amplification of chosen for molecular analysis $5 \mathrm{~s}$ rDNA-ISR and $\mathrm{CO} 1$ genes resulted in products 750 and $760 \mathrm{bp}$, respectively.

The sequencing of $5 \mathrm{~s}$ rDNA-ISR amplicons resulted in obtaining sequences from all five individual larvae. The total length of comparative alignment studied in this research was $730 \mathrm{bp}$. The obtained sequences of 5s rDNAISR from all five individual muscle larvae had $100 \%$ identical haplotype. Nucleotide sequence data obtained in the study were deposited in GenBank under the following accession number: KY436419. The total length of alignment of our $T$. nativa $5 \mathrm{~s}$ rDNA-ISR sequences with sequences from GenBank database was determine by length of shortest entry and were $463 \mathrm{bp}$ length. The phylogenetic analysis of obtained alignment from 5s rDNAISR sequences confirmed species identification of detected larvae as T. nativa. Furthermore, according to the generated phylogenetic tree, the analyzed sequences were clustered in separated clad with T. nativa and T6 (Fig. 1).

Sequence analysis of all five obtained $5 \mathrm{~s}$ rDNA-ISR sequences shows $99.8 \%$ of similarity with $T$. nativa AY009944, differing in one single nucleotide polymorphism in the position 136 (Table 1). The matrix identity analysis shows $99.1 \%$ identity with Trichinella T6 AY009948 with three SNP differences in position 93, 136, and 391 (Table 1).
The sequencing of a part of $\mathrm{CO} 1$ gene resulted in obtaining sequences from all five individual larvae. The total length of comparative alignment studied in this research was $750 \mathrm{bp}$. The obtained sequences of $\mathrm{CO} 1$ from all five individual muscle larvae had 100\% identical haplotype. Nucleotide sequence data obtained in the study were deposited in GenBank under following accession number KY486636. The total length of alignment of our T. nativa CO1 sequences with Trichinella sequences from GenBank database was determined by length of shortest entry and were 721-bp length. Phylogenetic analysis of obtained alignment from partial $\mathrm{CO} 1$ sequences also confirmed species identification of analyzed larvae. The obtained sequences of first detected in Poland T. nativa were clustered in one clad with others $T$. nativa chosen to analysis. The resulting clad was consist from five groups of $T$. nativa haplotypes, one of the group were created only from newly detected $T$. nativa (Fig. 2). Sequence analysis of all five obtained $\mathrm{CO} 1$ sequences show the highest $99.7 \%$ identity with $T$. nativa KU355857, KU355858, KU355859, KU355860, and KU355861. The detailed analysis of matrix identity shows from 99.2 to $99.7 \%$ identity with various $T$. nativa $\mathrm{CO} 1 \mathrm{se}$ quences and $99.2 \%$ identity with Trichinella T6. The investigated $\mathrm{CO} 1$ sequence differed between vary sequences of T. nativa deposited in GenBank from two to six single nucleotide polymorphisms (Table 2). 
Fig. 2. Phylogenetic tree of the partial of $\mathrm{CO} 1$ gene sequences from the Trichinella larvae. The phylogenetic tree was constructed using MrBayes analyses running the HKY model with burn in = 100,000 . The tree constructed using the Neighbor-Joining method with Jukes-Cantor model shows identical results, data not shown.

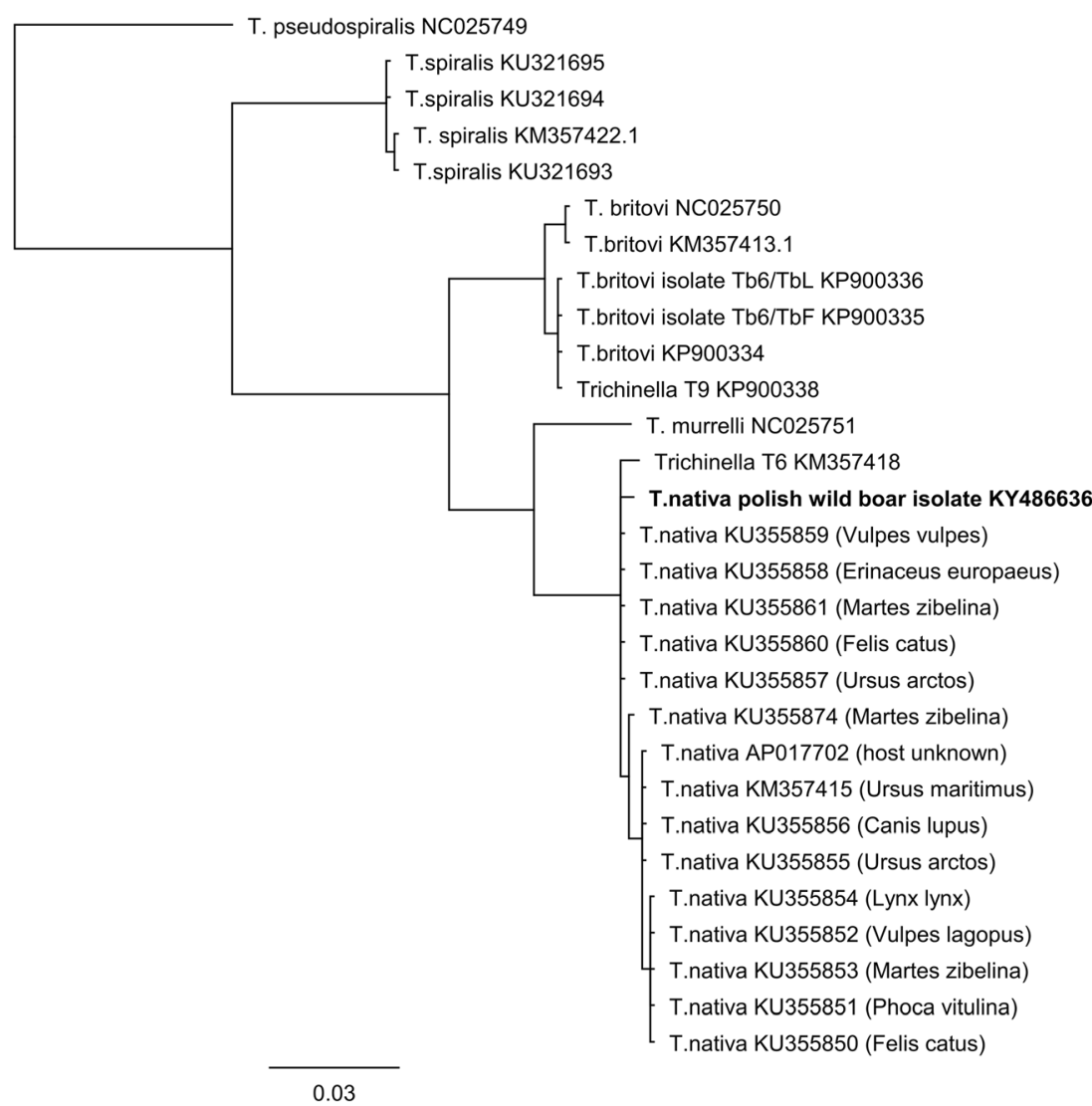

\section{Discussion}

In this study, we detected for the first time $T$. nativa in wild boar in Poland. This finding is not only one of several cases of T. nativa invasion in wild boars all over the world but also one of the very few cases of T. nativa detected so far beyond the known boundary of occurrence of this species. The natural geographic distribution of this cold-resistant species are arctic and subarctic areas of Holarctic regions. The border of the southern distribution of T. nativa has been identified between the isotherms -5 to $-4{ }^{\circ} \mathrm{C}$ in January (Pozio et al. 1992; Pozio and La Rosa 2000; Pozio and Murrell 2006). In Europe, the species was detected mostly in Finland, Sweden, Russia,
Estonia, Norway, Latvia, and Lithuania (Pozio 2016). The infected wild boar, described herein, was gained on the longitude and latitude $53^{\circ} 34^{\prime} 50^{\prime \prime} \mathrm{N}, 19^{\circ} 39^{\prime} 13^{\prime \prime} \mathrm{E}$. The closest to our finding wild boar infected by T. nativa were detected in Lithuania, more than $500 \mathrm{~km}$ far from this outcome (https:// www.iss.it, 2017.02.07). Our outcome is the first wild boar infected by $T$. nativa furthest to the South compared to the evidenced previously. Although occasional occurrence of this species below the known boundary were described, those cases were detected from other hosts. For example, findings of red foxes infected by this species in areas of Poland and Germany. The T. nativa isolate from red fox discovered in Poland in 2013 originated $150 \mathrm{~km}$ north-east
Table 1 Position of single nucleotide polymorphism between $T$. nativa $5 \mathrm{~S}$ rDNA-ISR haplotype generated in this study and sequences of other Trichinella species and genotypes

\begin{tabular}{llll}
\hline Nucleotide position/ Trichinella species & 93 & 136 & 391 \\
\hline T. nativa polish isolate KY436419 & $\mathrm{T}$ & $\mathrm{G}$ & $\mathrm{A}$ \\
T. nativa AY009944 & $\mathrm{T}$ & $\mathrm{C}$ & $\mathrm{A}$ \\
T6 AY009948 & $\mathrm{C}$ & $\mathrm{C}$ & $\mathrm{G}$ \\
T. spiralis KJ716745, AY009946 & $\mathrm{T}$ & $\mathrm{T}$ & $\mathrm{G}$ \\
T. britovi KP900342, AY009943, GU325734, GU325737 & $\mathrm{T}$ & $\mathrm{G} / \mathrm{C}$ & $\mathrm{G}$ \\
T. murelli AB426627 & $\mathrm{T}$ & $\mathrm{C}$ & $\mathrm{G}$ \\
T9 KP900345 & $\mathrm{T}$ & $\mathrm{C}$ & $\mathrm{G}$ \\
T. pseudospiralis AY009950 & $\mathrm{T}$ & $\mathrm{C}$ & $\mathrm{G}$ \\
T6 AY009948 & $\mathrm{T}$ & $\mathrm{G}$ & $\mathrm{A}$ \\
\hline
\end{tabular}


Table 2 Position of single nucleotide polymorphism between T. nativa CO1 haplotype generated in this study and sequences of other Trichinella species and genotypes

\begin{tabular}{|c|c|c|c|c|c|c|c|c|}
\hline Nucleotide position/ Trichinella species & 98 & 129 & 144 & 438 & 564 & 624 & 626 & 639 \\
\hline T. nativa polish isolate $\mathrm{KY} 486636$ & $C$ & $\mathrm{~T}$ & $A$ & $\mathrm{~T}$ & $\mathrm{C}$ & $\mathrm{T}$ & $\mathrm{C}$ & $\mathrm{T}$ \\
\hline T. nativa $\mathrm{KU} 355853$ & $\mathrm{~T}$ & $\mathrm{C}$ & $\mathrm{G}$ & $\mathrm{T}$ & $\mathrm{T}$ & $\mathrm{C}$ & $\mathrm{C}$ & $\mathrm{C}$ \\
\hline \multicolumn{9}{|l|}{$\begin{array}{l}\text { T. nativa KU355850, T. nativa KU355851, T. nativa } \\
\text { KU355854 }\end{array}$} \\
\hline T. nativa KU355857 & $\mathrm{T}$ & $\mathrm{T}$ & G & $\mathrm{T}$ & $\mathrm{C}$ & $\mathrm{T}$ & $\mathrm{C}$ & $\mathrm{T}$ \\
\hline \multicolumn{9}{|l|}{$\begin{array}{l}\text { T. nativa KU355858, T. nativa KU355859, T. nativa } \\
\text { KU355860 }\end{array}$} \\
\hline \multicolumn{9}{|l|}{ T. nativa KU355861 } \\
\hline T. nativa KU355855 & $\mathrm{T}$ & $\mathrm{T}$ & $\mathrm{G}$ & $\mathrm{T}$ & $\mathrm{C}$ & $\mathrm{C}$ & $\mathrm{C}$ & $\mathrm{T}$ \\
\hline \multicolumn{9}{|l|}{ T. nativa KU355856 } \\
\hline \multicolumn{9}{|l|}{ T. nativa $\mathrm{KM} 357415$} \\
\hline T. nativa DQ007891 & - & - & - & - & - & $\mathrm{C}$ & $\mathrm{C}$ & $\mathrm{T}$ \\
\hline T.nativa AF129489 & - & - & - & - & - & $\mathrm{T}$ & $\mathrm{C}$ & $\mathrm{T}$ \\
\hline T. nativa AP017702 & - & - & - & - & - & $\mathrm{T}$ & $\mathrm{C}$ & $\mathrm{T}$ \\
\hline T. nativa AB252966 & - & - & - & - & - & $\mathrm{T}$ & $\mathrm{C}$ & $\mathrm{C}$ \\
\hline T. nativa KU355874 & $\mathrm{T}$ & $\mathrm{C}$ & G & $\mathrm{T}$ & $\mathrm{C}$ & $\mathrm{T}$ & $\mathrm{C}$ & $\mathrm{T}$ \\
\hline T6 KM357418 & $\mathrm{T}$ & $\mathrm{T}$ & G & $\mathrm{C}$ & $\mathrm{T}$ & $\mathrm{T}$ & $\mathrm{T}$ & $\mathrm{T}$ \\
\hline $\begin{array}{l}\text { T. spiralis KU321694, KU321695, KM357422.1, } \\
\text { KU321693 }\end{array}$ & $\mathrm{T}$ & $\mathrm{T}$ & A & $\mathrm{C}$ & $\mathrm{T}$ & $\mathrm{C}$ & $\mathrm{T}$ & $\mathrm{C}$ \\
\hline $\begin{array}{l}\text { T. britovi NC025750, KM357413, KP900336, } \\
\text { KP900335, KP900334 }\end{array}$ & $\mathrm{T}$ & $\mathrm{T}$ & A & $\mathrm{T}$ & $\mathrm{C}$ & $\mathrm{T}$ & $\mathrm{C}$ & $\mathrm{T}$ \\
\hline T. murelli $\mathrm{NC} 025751$ & $\mathrm{~T}$ & $\mathrm{~T}$ & A & $\mathrm{T}$ & $\mathrm{T}$ & $\mathrm{T}$ & $\mathrm{C}$ & $\mathrm{C}$ \\
\hline T9 KP900338 & $\mathrm{T}$ & $\mathrm{T}$ & A & $\mathrm{T}$ & $\mathrm{C}$ & $\mathrm{T}$ & $\mathrm{C}$ & $\mathrm{T}$ \\
\hline T. pseudospiralis NC025749 & $\mathrm{T}$ & $\mathrm{T}$ & $\mathrm{A}$ & $\mathrm{C}$ & $\mathrm{T}$ & $\mathrm{T}$ & $\mathrm{C}$ & $\mathrm{C}$ \\
\hline
\end{tabular}

far from the case of investigated herein wild boar (Chmurzynska et al. 2013). In Germany, the two red foxes infected by T. nativa were found 700 and $1200 \mathrm{~km}$ far to the south of known boundary of occurrence of this cold-resistant species (Chmurzynska et al. 2013). These geographic localizations of wild boar described here confirm results of previous researchers that the area of occurrence of $T$. nativa is spread onto new regions and new host species (Pozio and La Rosa 2000; Chmurzynska et al. 2013; Kirjusina et al. 2015; Pozio 2016).

The occurrence of this case have to be highlighted also because this is the first wild boar found to be infected by T. nativa in Central Europe. This species is known as the typical subarctic species of parasite, most often detected from terrestrial and marine carnivores (Gottstein et al. 2009; Kirjusina et al. 2015; Pozio 2016; Deksne et al. 2016; Odoevskaya and S. E. S. 2016). The carnivores had been described as typical host for this taxa and parasite can stay infected in muscle tissue of these animals at least 20 years (Kumar et al. 1990). It has to be underlined that both domestic pigs and wild boars are not common hosts for T. nativa (Kapel and Gamble 2000; Kapel 2001; Nockler et al. 2005; Hill et al. 2009). The tenacity study of this species indicates that their survival time in frozen meat is incomparable longer to other Trichinella species, especially to $T$. spiralis. Presented data in several studies indicate that T. nativa can survive in $-18^{\circ} \mathrm{C}$ for
5 years in polar bear, 4 years in arctic fox, and 1.5 year in wolf muscles (Dies 1980; Kapel et al. 1999; Dick and E. P. 2001). Those animal species are considered as typical hosts for T. nativa. It has to be highlighted that the survival time in wild boar muscles had not been recognized. However, for the experimentally infected domestic pigs, the survival time in $-6.6^{\circ} \mathrm{C}$ was $106 \mathrm{~h}$ (Hill et al. 2009). So that we can cautiously hypothesize that the time of resistance of this species in the wild boars muscles could be similar. Up to now, only several cases of wild boars infected by these cold-resistant species were evidenced (Kirjusina et al. 2015; Pozio 2016). The database of European Reference Laboratory reach 518 records of T. nativa from all over the world. Most of the cases are originated from lynx, red foxes, wolfs, black bears, wolverines, polar bears, and marine mammals and only eight cases were isolated from wild boars muscles (https://www.iss.it, 2017.02. 07).

As the cases of detection of T. nativa in wild boars are very seldom, the molecular characterization of the parasite strains isolated from this host is incomplete. The genetic data available in GenBank are very limited. Therefore, in this study, for molecular analysis most often amplified in genetic studies, $\mathrm{CO} 1$ gene was used. According to available literature and genetic data, it seems that $\mathrm{CO} 1$ gives more opportunities to find possible differences between T. nativa strains compared to genes used in previous researches (cytB, 18s rDNA) 
(Odoevskaya and S. E. S. 2016). Additionally, in the study, we amplify and analyze also part of nuclear gene $5 \mathrm{~s}$ rDNA-ISR. This gene was chosen especially for confirmation of species identification of multiplex PCR results. The database of both investigated parts of genes are not rich in sequences of T. nativa, especially from wild boars. Therefore, phylogenetic analysis was done on limited numbers of sequences from strains of T. nativa originated from different hosts excluding wild boars. The molecular analysis of 5s rDNA-ISR gene confirmed results of species identification done by multiplex PCR and showed that those detected in this study larvae belongs to the clad with other previously detected $T$. nativa. Unfortunately, the comparison of obtained sequences with those from GenBank was hampered by the shorter sequences, which caused excluding from alignment most of the deposited previous sequences. The highest identity with our 5s rDNAISR sequences shows $T$. nativa originated from polar bear (Ursus maritimus). The polar bear was detected in 1984 in Norway (Rombout et al. 2001b). The discovered one single nucleotide polymorphism between our sequences and this from polar bear indicate on occurrence of some genetic differences between T. nativa strains (Table 1). However, too less number of the $5 \mathrm{~s}$ rDNA-ISR sequences of $T$. nativa in current study cause that further conclusions based on this analysis are impossible.

The phylogenetic analysis of $\mathrm{CO} 1$ sequences gives more robust comparison, because of evidence of higher number T. nativa sequences available in GenBank database and which were used in alignment. The analysis clustered our CO1 T. nativa sequences in one clad with the rest investigated T. nativa (Fig. 2). The indicated identity of our CO1 T. nativa sequences of 99.7 and $99.3 \%$ with sequences originated from Russia and Norway, confirm correct species identification but also show the differences between our sequences and these used in analysis. The discovered differences were shown in alignment, where several SNP's between analyzed T. nativa sequences were detected (Table 2). Furthermore, two of SNP's in position 98 (transition from $\mathrm{T}$ to $\mathrm{C}$ ) and 144 (transition from $\mathrm{G}$ to $\mathrm{A}$ ) were new substitutions comparing to the sequences previously deposited in GenBank, which means that this is a new T. nativa haplotype. However, it has to be highlighted that none of the CO1 sequences used in the study for alignment were from wild boars. The sequences from GenBank used for alignment originated from brown bears (Ursus arctos), lynx (Lynx lynx), seal (Phoca vitulina), stray cat (Felis catus), polar fox from fur farm (Vulpes lagopus), wolf (Canis lupus), hedgehog (Erinaceus europaeus), sables (Martes zibelina), and polar bear ( $U$. maritimus). The analysis of these sequences do not show any significant connection of obtained haplotypes with host species. For example, in three sables three different haplotypes of $\mathrm{CO} 1$ sequences were found (Fig. 2). More probable is connection of $\mathrm{CO} 1$ T. nativa haplotypes with geographical origin of the hosts. The CO1 T. nativa sequences used in the analysis (besides our polish isolate) were originated in majority from Russia (13 sequences), Norway (1), and one with unknown origin. Our outcome confirm data presented by Odoevskaya and S. E. S. (2016), who reported several haplotypes of $T$. nativa discovered in various regions of Russia and concluded that haplotypes can be connected with the geographical origin of host. However, a small number of sequences which is noticed up to now and was used in the analysis limits possibilities to draw definitive conclusion.

The occurrence of several haplotypes of CO1 indicate on high genetic variation in this species of Trichinella nematodes. This could mean that $T$. nativa is a less homogeneous taxa compare to T. spiralis (Franssen et al. 2015; La Rosa et al. 2012) and may have higher amount of haplotypes, like for example, observed in T. britovi (Franssen et al. 2015). Furthermore, in the study observed, the high identity (99.2\% in CO1 alignment) of investigated T. nativa sequences to T6 sequence. This could be explained by deriving both genotypes $T$. nativa and T6 from one linage (Korhonen et al. 2016).

\section{Conclusions}

The first detection of T. nativa in wild boar in Poland is next evidence for the spread of this species on the new regions of Europe. This freeze-resistant species, rarely detected in wild boars, is infective for humans. T. nativa may cause danger for humans, who may acquire infection directly by consumption of meat of wild boar or indirectly by other infected vectors. Newly discovered haplotypes in current study (both, in 5 rDNA-ISR sec. and CO1 genes) are showing singlenucleotide differences compared with sequences deposited in GenBank and could indicate on high variation between T. nativa strains from various geographical region of host origin.

Acknowledgements This work was partially supported by the Polish Ministry of Agriculture and Rural Development (in the frame of Multiannual Programme "Protection of animal and public health").

\section{Compliance with ethical standards}

Conflict of interests The authors declare no conflict of interests.

Open Access This article is distributed under the terms of the Creative Commons Attribution 4.0 International License (http:// creativecommons.org/licenses/by/4.0/), which permits unrestricted use, distribution, and reproduction in any medium, provided you give appropriate credit to the original author(s) and the source, provide a link to the Creative Commons license, and indicate if changes were made. 


\section{References}

Bilska-Zając E, R. M., Chmurzyńska E, Karamon J, Cencek T (2013) Trichinella species circulating in wild boar (Sus scrofa) populations in Poland. Int J Parasitol Parasit Wildlife 2:211-213

Bilska-Zajac E, Rozycki M, Chmurzynska E, Karamon J, Sroka J, Antolak E, Prochniak M, Cencek T (2016) First record of wild boar infected with Trichinella pseudospiralis in Poland. J Vet Res 60: $147-152$

Chmurzynska E, Rozycki M, Bilska-Zajac E, Nockler K, Mayer-Scholl A, Pozio E, Cencek T, Karamon J (2013) Trichinella nativa in red foxes (Vulpes vulpes) of Germany and Poland: possible different origins. Vet Parasitol 198:254-257

G Deksne, Z. S.., I Jahundoviča, Z Esīte, E Bakasejevs, G Bagrade, 2016 High prevalence of Trichinella spp. in sylvatic carnivore mammals of Latvia. Vet. Parasitol

Dick TA, E. P. (2001) Trichinella spp. and Trichinellosis. Iowa State University Press, Ames, Iowa, pp 380-396

Dies K (1980) Survival of Trichinella spiralis larvae in deep-frozen wolf tissue. Can Vet J 21:38-38

Franssen F, Bilska-Zajac E, Deksne G, Sprong H, Pozio E, Rosenthal B, Rozycki M, van der Giessen J (2015) Genetic evidence of interspecies introgression of mitochondrial genomes between Trichinella spiralis and Trichinella britovi under natural conditions. Infect Genet Evol 36:323-332

Gottstein B, Pozio E, Nockler K (2009) Epidemiology, diagnosis, treatment, and control of Trichinellosis. Clin Microbiol Rev 22:127-+

Hill DE, Forbes L, Zarlenga DS, Urban JF, Gajadhar AA, Gamble HR (2009) Survival of north American genotypes of Trichinella in frozen pork. J Food Protect 72:2565-2570

Kapel CMO (2001) Sylvatic and domestic Trichinella spp. in wild boars; infectivity, muscle larvae distribution, and antibody response. J Parasitol 87:309-314

Kapel CMO, Gamble HR (2000) Infectivity, persistence, and antibody response to domestic and sylvatic Trichinella spp. in experimentally infected pigs. Int J Parasitol 30:215-221

Kapel CMO, Pozio E, Sacchi L, Prestrud P (1999) Freeze tolerance, morphology, and RAPD-PCR identification of Trichinella nativa in naturally infected arctic foxes. J Parasitol 85:144-147

Kearse M, Moir R, Wilson A, Stones-Havas S, Cheung M, Sturrock S, Buxton S, Cooper A, Markowitz S, Duran C, Thierer T, Ashton B, Meintjes P, Drummond A (2012) Geneious basic: an integrated and extendable desktop software platform for the organization and analysis of sequence data. Bioinformatics 28:1647-1649

Kirjusina M, G Deksne, G Marucci, E Bakasejevs, I Jahundovica, A Daukste, A Zdankovska, Z Berzina, Z Esite, A Bella, F Galati, A
Krumina, E Pozio 2015 A 38-year study on Trichinella spp. in wild boar (Sus scrofa) of Latvia shows a stable incidence with an increased parasite biomass in the last decade. Parasite Vector 8

Korhonen PK, E Pozio, G La Rosa, B CH Chang, AV Koehler, EP Hoberg, P R Boag, P Tan, AR Jex, A Hofmann, PW Sternberg, ND Young and RB Gasser 2016: Phylogenomic and biogeographic reconstruction of the Trichinella complex. Nat Commun, 7

Kumar V, Pozio E, Deborchgrave J, Mortelmans J, Demeurichy W (1990) Characterization of a Trichinella isolate from polar bear. Ann Soc Belg Med Tr 70:131-135

La Rosa G, Marucci G, Rosenthal BM, Pozio E (2012) Development of a single larva microsatellite analysis to investigate the population structure of Trichinella spiralis. Infect Genet Evol 12:369-376

Liu LX, Blaxter ML, Shi A (1996) The 5S ribosomal RNA intergenic region of parasitic nematodes: variation in size and presence of SL1 RNA. Mol Biochem Parasitol 83:235-239

Nockler K, Serrano FJ, Boireau P, Kapel CMO, Pozio E (2005) Experimental studies in pigs on Trichinella detection in different diagnostic matrices. Vet Parasitol 132:85-90

Odoevskaya IM, S. E. S. (2016) Trichinella nativa haplotypes in Russia show diversity in cytochrome oxidase mtDNA gene. Vet Parasitol 231:39-42

Popczyk B 2016: Zarządzanie populacją dzika Sus scrofa w Polsce

Pozio E (2016) Adaptation of Trichinella spp. for survival in cold climates. Food and Waterborne Parasitology 4:4-12

Pozio E, La Rosa G (2000) Trichinella murrelli n. sp: etiological agent of sylvatic trichinellosis in temperate areas of North America. J Parasitol 86:134-139

Pozio E, Murrell KD (2006) Systematics and epidemiology of Trichinella. Advances in Parasitology, Vol 63(63):367-439

Pozio E, Zarlenga DS (2013) New pieces of the Trichinella puzzle. Int J Parasitol 43:983-997

Pozio E, Shaikenov B, Larosa G, Obendorf DL (1992) Allozymic and biological characters of Trichinella-Pseudospiralis isolates from free-ranging animals. J Parasitol 78:1087-1090

Rombout YB, Bosch S, Mandjes B, Homan W, van der Giessen JWB (2001a) Genetic diversity within the genus Trichinella as shown by cleavage fragment length polymorphism analysis. J Helminthol 75: $67-72$

Rombout YB, Bosch S, Van der Giessen JWB (2001b) Detection and identification of eight Trichinella genotypes by reverse line blot hybridization. J Clin Microbiol 39:642-646

Zarlenga DS, Chute MB, Martin A, Kapel CMO (1999) A multiplex PCR for unequivocal differentiation of all encapsulated and nonencapsulated genotypes of Trichinella. Int J Parasitol 29:1859-1867 